\title{
Teacher-Student's Instructional Communication: A Case Study of Students with Attention Deficit Hyperactivity Disorder (SwADHD) in Inclusive Classroom
}

\author{
Annisa Nurul Hidayah ${ }^{1}$, Rasmitadila ${ }^{1}$ and Teguh Prasetyo ${ }^{1}$
}

${ }^{1}$ Universitas Djuanda, Indonesia

\footnotetext{
HOW TO CITE:

Nurul Hidayah, A., Rasmitadila,

Prasetyo, T. (2020).

Teacher-Student's Instructional

Communication: A Case Study

of Students with Attention Deficit

Hyperactivity Disorder (SwADHD)

in Inclusive Classroom.

International Journal of Special

Education, 35(2), 63-72

CORRESPONDING AUTHOR:

Rasmitadila;

Rasmitadila@unida.ac.id

DOI:

https://doi.org/10.52291/

ijse.2020.35.14

COPYRIGHT STATEMENT:

Copyright: (C) 2020 Authors.

Open access publication under the terms and conditions of the Creative Commons

Attribution (CC BY)

license (http://creativecommons.

org/licenses/by/4.0/).
}

\section{ABSTRACT}

The purpose of this study is to explore the types of instructional communication between general teacher (GT) and ADHD students (SwADHD) during activities of the: pre-instructional, instructional process, and instructional evaluation. Data collection was carried out by observation and interviews. The data analysis used was thematic analysis. The results showed that the types of instructional communication between GT and SwADHD were: verbal, non-verbal, and verbal-non-verbal. The three types of instructional communication aim to: improve the socio-emotional relationship between GT and SwADHDs, reduce negative behavior that often appears in SwADHDs in the classroom, and improve quality of instruction; to achieve quality educational goals according to their characteristics and needs. The type of communication used between GT and SwADHDs has a significant impact on teachers in developing individual education programs. These result in a more humane experience for SwADHDs both academically and non-academically .

Keywords: instructional communication; attention deficit hyperactive disorder; verbal; non-verbal; inclusive classroom 


\section{INTRODUCTION}

Communication is an important aspect of successful instruction. especially in inclusive classrooms consisting of students with diverse characteristics and unique learning styles. The success of instruction in an inclusive classroom is strongly influenced by the instructional interactions between all class members (Óskarsdóttir et al., 2020). Communication between: students, students-teachers, and general teachers-special teachers must be structured normally to be carried out properly. For this reason, teachers must be able to design instruction that promotes multidirectional communication, so that instructional objectives can be achieved (Fuentes et al., 2017). The diversity of students' characteristics and needs causes teachers to use various communication types with students who have special needs, including those with attention deficit hyperactive disorder (ADHD).

$\mathrm{ADHD}$ is commonly defined as impaired concentration and hyperactivity. This term provides a general description of internationally validated medical conditions that include: brain dysfunction, resulting in individuals having difficulty controlling impulses, inhibiting behavior, and being easily distracted (Sjöberg \& Dahlbeck, 2018; Russell et al., 2016). Students with ADHD (SwADHD) experience learning difficulties that must be the teacher's concern in learning (Wei et al., 2014). SwADHDs can experience: various learning difficulties, behavioral difficulties, social difficulties, communication difficulties, and other interrelated difficulties (Rodríguez et al., 2015). This must be a concern for teachers in schools, especially in inclusive schools, to handle SwADHD (Laasonen et al., 2014; Shillingford-Butler $\&$ Theodore, 2012). If this condition is ignored, it will have an impact on achievement and results in schools. Another consequence is that children may not graduate from school, and it is possible for them to drop out of school with all the problems that can arise. Some of the characteristics and learning barriers experienced by SwADHD are not understanding how to complete assignments and having excessive student motor activity (Barkley \& Poillion, 1994; Reebye, 2008). Students cannot sit for too long, so they run around in class or disturb their peers. Students show impulsivity and decreased learning concentration.

Communication barriers are also experienced by SwADHD, such as reduced use of verbal communication, difficulty expressing opinions and a tendency to hide feelings (so that the behavior exhibited appears excessive). SwADHD's concentration problems make it difficult to communicate. The results of other studies suggest that learning concentration in SwADHD is indicated by the behavior of not listening to the teacher's instructions and often disturbing friends (Ross \& Randolph, 2016). The causes of the communication barriers experienced by SwADHD can be attributed to the type of communication applied in learning. The role of communication between teachers and SwADHD is significant in: the pre-instructional, instructional process, and instructional evaluation (Hamilton \& Astramovich, 2016).

In Indonesia, the number of SwADHD show an increasing trend from year to year. The increasing number of SwADHD certainly gives larger assignments to general teachers (GTs) in order for instruction to run well. Like other inclusive classrooms, communication between GT and SwADHD is one of the keys to successful instruction. The diverse backgrounds of SwADHDs in inclusive classrooms in Indonesia, such as family backgrounds (for example, weak economy), parenting styles in educating SwADHDs at home, and the external environment of SwADHDs all provide different styles of communication (Rosita et al., 2020). This condition affects the choice of communication type that GTs use with SwADHD in the classroom. Despite facing similar obstacles, such as difficulty concentrating, being easily distracted from an activity, a tendency to annoy by friends. SwADHD from different backgrounds, require different communication types to be used by the GT (Rief, 2012). Furthermore, the communication differences between SwADHDs make it difficult for GTs to implement the type of communication that matches the characteristics of SwADHDs. Although previous research results have revealed many communication difficulties faced by SwADHDs, the socio-cultural conditions and differences in the backgrounds of students make Gts role in Indonesia more difficult. In the end, it is difficult to achieve the goals and quality in the SwADHDs learning.

Instructional communication between GTs and SwADHD in inclusive classrooms in Indonesia uses verbal and non-verbal communication types. Verbal communication is focused on making SwADHDs follow instructions or commands given by GTs to SwADHDs. Meanwhile, non-verbal communication is usually a type of supporting communication (Humairah, 2017). Some examples of non-verbal communication that GTs often 
use include: smiling, touching, face to face as an open symbol and sign of approval, or praise to SwADHDs. As a socio-cultural manifestation of Indonesian society, especially in education, an example is-kissing the back of a teacher's handthis is a type of communication strengthening the psychosocial relationship between teachers and students (Dasrial et al., 2020). Apart from being a form of respect for educators or elders, it is also an expression of affection between students and teachers (Farida \& Friani, 2018). This activity is a type of non-verbal communication between GTs and SwADHDs, so that teachers can find out the readiness of SwADHD to start instruction and a form of thanks for SwADHDs when completing instruction. To achieve the instructional objectives for SwADHDs in Indonesia, it is essential to vary the types of communication according to the characteristics of SwADHDs to meet their needs. GTs must be able to use the type of communication that matches the strengths of SwADHDs and even socio-cultural approaches that can support successful learning.

This study aims to explore the type of instructional communication between general teachers (GT) and students with ADHD (SwADHD) during: pre-instructional, instructional, and instructional evaluation in inclusive classrooms.

\section{METHODOLOGY}

\section{Research Design}

This research used case studies. Case studies are usually used for: special education, psychology and inclusive education (Moeller et al., 2015). A single case is also well suited for studies with only 3-10 participants (Kennedy, 2005). Additionally, case studies aim to provide flexibility for researchers to obtain data from a particular phenomenon or context. This study explores the phenomena associated with the communication process between GT and SwADHDs from pre-instructional until instructional evaluation. A literature review was carried out to determine the conceptual and operational definitions. Specifically for the communication process in every learning activity used in an inclusive classroom (Tuckman \& Harper, 2012). Furthermore, the research instrument in the form of an observation sheet was prepared to determine all activities related to communication between GTs and SwADHDs. In addition to the observation sheet, the interview instrument was also prepared to expand upon information about the type of communication between GTs and SwADHDs.

\section{Participants}

Participants in this study consisted of eleven students, consisting of three SwADHDs and eight general students (GS) at one of the inclusive public elementary schools in West Java province, Indonesia. The selection of the three SwADHDs in this study used school psychologists' assessment results with ADHD characteristics. Specifically, the characteristics of SwADHDs in this study, see Table 1.

\begin{tabular}{|c|c|c|c|c|c|}
\hline $\begin{array}{l}\text { Initial } \\
\text { name }\end{array}$ & $\begin{array}{c}\text { Age } \\
\text { (years) }\end{array}$ & Sex & $\begin{array}{l}\text { Academic } \\
\text { ability }\end{array}$ & $\begin{array}{l}\text { Personal } \\
\text { ability }\end{array}$ & $\begin{array}{l}\text { Family's } \\
\text { background }\end{array}$ \\
\hline $\mathrm{KW}$ & 10 & Female & $\begin{array}{l}\text { - Likes art lessons. } \\
\text { - Achievement of learning } \\
\text { outcomes for mathematics is low. } \\
\text { - Like science lessons with } \\
\text { practical methods/observation. } \\
\text { - Likes language lessons. }\end{array}$ & $\begin{array}{l}\text { - Short concentration span. } \\
\text { - Lack of focus. } \\
\text { - Low learning motivation. } \\
\text { - Difficulty communicating } \\
\text { with others }\end{array}$ & $\begin{array}{l}\text { - Pay attention to KW, } \\
\text { including growth } \\
\text { and development. } \\
\text { - Have brought KW to child } \\
\text { psychologists for further } \\
\text { analysis. }\end{array}$ \\
\hline SA & 10 & Male & $\begin{array}{l}\text { - Likes subjects that rely on } \\
\text { a physical aspect, such as sports. } \\
\text { - Dislikes language lessons } \\
\text { and Mathematics (low learning } \\
\text { outcomes). } \\
\text { - Likes science lessons with } \\
\text { the method of observation/practice. }\end{array}$ & $\begin{array}{l}\text { - Short concentration span. } \\
\text { - Very active. } \\
\text { - Difficult to communicate } \\
\text { - Quick to anger } \\
\text { - Motivation to learn will be high } \\
\text { if given a reward. }\end{array}$ & $\begin{array}{l}\text { - SA does not get enough } \\
\text { attention from the family } \\
\text { because parents are busy } \\
\text { working and give up learning } \\
\text { ability to GT in school. }\end{array}$ \\
\hline $\mathrm{NI}$ & 11 & Male & $\begin{array}{l}\text { - Does not like math } \\
\text { and language lessons. } \\
\text { - Enjoys sports. } \\
\text { - Likes lessons in art/singing. }\end{array}$ & $\begin{array}{l}\text { - Low learning motivation } \\
\text { - Low concentration span } \\
\text { - Very active } \\
\text { - Difficult to communicate with } \\
\text { other people }\end{array}$ & $\begin{array}{l}\text { - Parents always ask GT } \\
\text { about NI's progress, } \\
\text { especially in activities } \\
\text { that NI likes. }\end{array}$ \\
\hline
\end{tabular}




\section{Data Collection}

Data collection was carried out in two stages. The first stage was carried out by classroom observations, with three SwADHDs and eight GSs in each instructional activity. Observations were made for five meetings, with the observation's duration ranging from $07.00 \mathrm{am}-4.00 \mathrm{pm}$. Researchers used observation instruments containing instructional activities to obtain observational data, from pre-instruction until instructional evaluation (for one meeting). The contents of the observation instrument were focused on the communication process between GTs and SwADHDs. After carrying out observations for five meetings, the researcher conducted interviews with GTs during a special time so that GT could focus more on explaining the characteristics of SwADHDs. Interviews were conducted using semi-structured techniques and open-ended questions. GT's number of questions totaled five questions: communication types, communication problems faced by GT with SwADHDs (inside and outside the classroom), and how to communicate between GT and SwADHDs. Interviews were conducted for two consecutive days, with a duration of 1.5-2 hours face to face.

\section{Data Analysis}

Data analysis techniques were analyzed using thematic analysis to identify, evaluate, and create themes expressed by participants (Clarke et al., 2015). Observation data and interview data were recorded in a manuscript (verbatim manuscript) and coded for each one not to overlap. The coding was done using a combination of deductive and inductive techniques. At the beginning of the study, the researcher determined the initial code for the three focuses, namely, activities on the pre-instruction, instructional process, and instructional evaluation.
Furthermore, it was done inductively by filtering and generating new code by iterating the code when filtering data. To simplify the data analysis process, the researcher used the NVivo 12 program in the coding and categorization process of each finding. Data from observations and interviews were entered into Nodes and Cases to be grouped into data with a specific code. Thematic maps show the organization of concepts according to various levels, and potential interactions between concepts are then developed. Researchers analyze and discuss all codes and categorizations and the possible integration between codes to be streamlined. This inductive technique allows identifying themes given by participants in response to research questions (Liu, 2011). See Figure 1 below:

The credibility and dependability of data in this study are considered a form of data validity that can be justified. The data credibility procedure starts with preparing a data collection instrument that uses a review of the relevant literature. The observation and interview instruments were designed and validated by two experts: one of inclusive education and one of instructional design. After the data was collected, the data's credibility was carried out by member checking, especially in the interview data. The researcher confirmed the transcript and data analysis results with the GT so that the data was guaranteed to be accurate. The use of source triangulation and investigator triangulation involving the three researchers also added to dependability (Patton, 2014). Furthermore, researcher triangulation was also carried out to reduce bias by facilitating member-checking to check the integrity of participants' responses (Treharne \& Riggs, 2015). All researchers' involvement was essential to produce findings' with integrity from different points of view of the same problem.

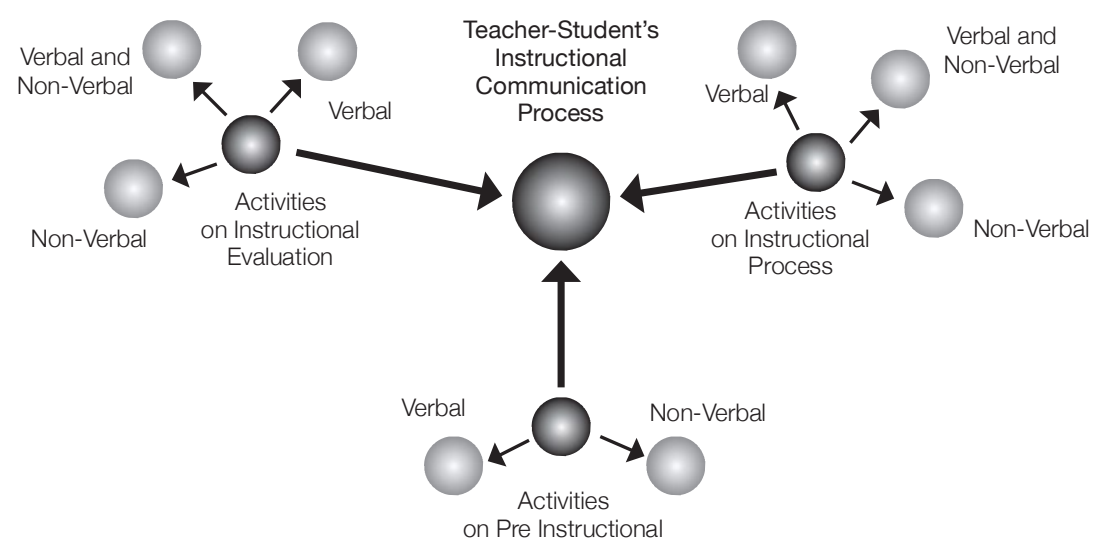

Figure 1.

Results of Data Analysis from the Teacher-Student's Instructional Communication Process. 


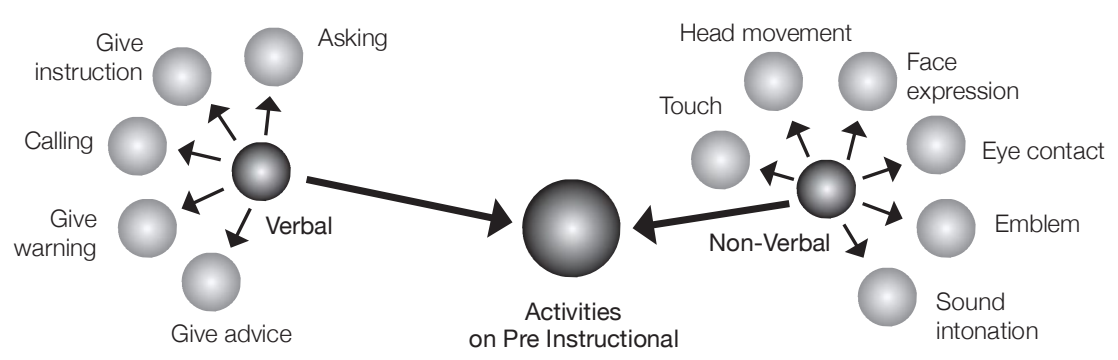

Figure 2.

Types of Communication between SwADHD and DT in Pre-Instructional Activities

\section{FINDINGS}

\section{Pre-Instructional}

Pre-instructional activity is one of the pre-instructional activities carried out between SwADHDs and GTs. All communication processes that occur in the preparation for core instructional activities occur prior to instruction.

Pre-instructional activities consist of two themes, namely the types of verbal and non-verbal communication. The type of verbal communication consists of: giving advice, admonitions, instructions, calls, and questions. Verbal communication when giving advice aims to motivate SwADHDs to be enthusiastic in starting instructional activities. SwADHDs gave a positive response in preparing themselves to learn, such as the sentence „Yes, Miss.” In giving reprimands and instructions, verbal communication aims to make SwADHDs immediately occupy a seat, indicating that instructional activities will begin. SwADHD understand that instruction is about to begin and has begun to take their seats through reprimands and hints. Apart from that, the warning and hint from GT are intended so that SwADHDs do not disturb their other friends. Examples of GT reprimands include:

GT : "Come on SA, don't bother your friends, take your seat now because we are going to start studying."

SA : „Ah, Miss, what's wrong? (While stopping annoying friends and going to her seat)

The other verbal communication is calling and asking questions to open communication when the GT meets $\mathrm{SwADHD}$ s when they enter the class. GT calls the name of SwADHDs, and asks about the condition of SwADHDs (example: „how are you today?”). SwADHDs answer GT and are accompanied by school culture of kissing the back of GT's hand. The culture of kissing GT's hand is one of the school cultures that aims to make students respect teachers as parents and understand what a student should and should not do to teachers (Dasrial et al., 2020). It aims to foster closeness between the GT and SwADHDs so that they have a sense of being more open: in expressing opinions, self-confidence and creating a good social relationship.

Types of non-verbal communication consist of emblems, head movements, facial expressions, eye contact, and touch. The use of emblems and head movements is a type of non-verbal communication that aims to provide signals (the use of thumbs and head movements) so that SwADHDs follow instructions and, if successful, follow GT instructions. The GT gave instructions in the form of a warning to SwADHDs by shaking their head. Meanwhile, using thumbs and nodding the head when SwADHDs follow GT instructions. The GT used facial expressions and eye contact when giving reprimands with stern facial expressions. The GT made a smiling face when SwADHDs successfully followed the instructions and reprimands. SwADHDs usually gave a smiling face when GT complimented them on executing their instructions well. Facial expressions are usually followed by eye contact between the GT and SwADHDs. This can be seen from the results of the interview with GT:

GT : "I usually give a smile to SwADHDs if they are successful in carrying out my instructions well, besides, of course, always making eye contact with them."

The teacher uses non-verbal communication in the form of touch by touching the back of SwADHDs to inquire about the news and condition of SwADHDs. Apart from that, a touch to the students' heads when the GT gives advice and motivates SwADHDs to be ready to learn. SwADHDs regularly nodded their heads as a sign of approval of what GT had said.

Types of verbal and nonverbal communication between GT and SwADHDs in pre-instructional activities aim to ensure the readiness of SwADHDs to start learning. The readiness of SwADHDs is focused on the socio-emotional aspect so that they are ready to build relationships with friends and their environment, but can provide attention and reduce impulsivity when learning. 


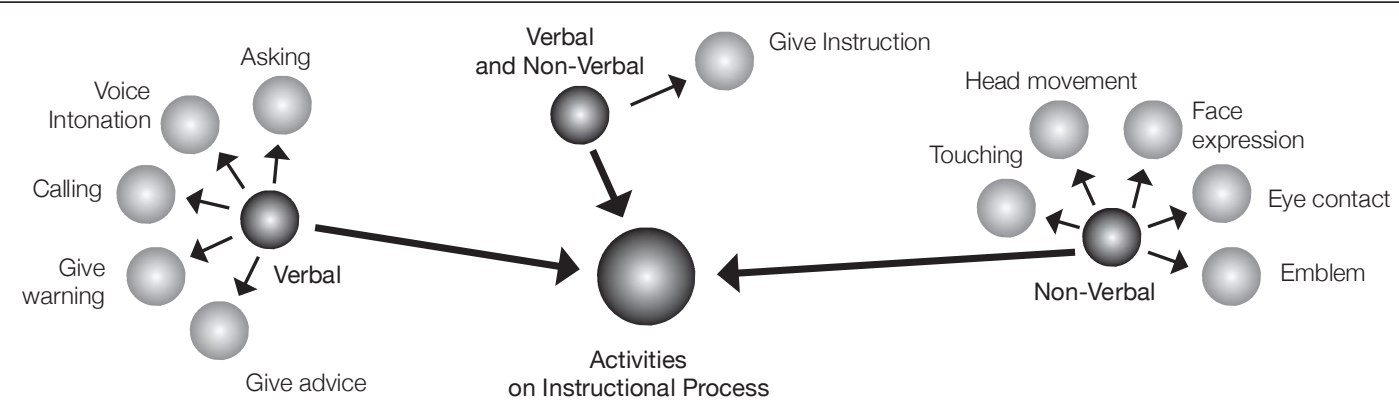

Figure 3.

Types of communication between SwADHD and GT on Instructional Process Activities

\section{Instructional Process}

There are three themes of communication types in instructional activities: verbal, non-verbal, and both verbal and non-verbal. The communication process that occurs between GTs and SwADHDs in instructional activities is a type of communication in both academic and non -academic aspects given by the GT to all class members.

Verbal communication consists of: giving advice, admonitions, calls, questions, and voice intonation. Giving advice and reprimands is a type of communication between GTs and SwADHDs, aiming to ensure that SwADHDs carry out instructions, assignments, and social interactions with other students (Tannock, 2018). The GT provides advice to SwADHDs, usually in verbal sentences, to emphasize that SwADHDs listens to the GT's advice and implements the advice. For example, the GT advises NI to sit in his chair while doing assignments (done repeatedly). NI responds to non-verbal communication by sitting in his chair but necessitating communication repetition by running in the classroom. Apart from advice, the warning also had the same objective: asking SwADHDs to carry out the GTs instructions (Saussure \& Rocci, 2016). For example, the GT admonished KW to do the assignment in his chair, not to disturb his friends and immediately carry out the assigned task. KW responded non-verbally by adhering to all the warnings given by the GT. Call and ask communication types are two types of verbal communication that aim to: ensure that SwADHDs always focus or pay attention to the subject matter, ensure that SwADHDs understand the subject matter, and understand the instructions given by the GT to SwADHDs. The GT ensures that SwADHDs is focused on the given task in the call communication type and has correctly identified the instructions. After calling, the GT will usually ask questions and ensure that the GT's assignments and materials are correct. The SwADHD usually responds by asking GT again about the tasks that must be done. For example:

\section{GT: „SA (calling names), what are you doing? Have you done the task that you gave me?"}

SA: "What was your job, Miss?"

Another type of verbal communication, namely voice intonation, is the GT's communication type when explaining material repeatedly to SwADHDs, both at moderate and slow levels. The type of voice intonation communication depends on the condition of the SwADHDs (Borkowska \& Zawadzka, 2008). The psychological condition of SwADHDs very much determines the medium, high and low tone of voice used.

Types of non-verbal communication consisting of: emblems, facial expressions, head movements, eye contact, and touch (Boyce, 2017). This type of emblem communication is used by GTs implementing a certain hand wave or gesture. The goal is that SwADHDs focus on and understand the material described by GT. SwADHDs were given various responses (such as pointing fingers and smiles), indicating that SwADHDs understood the material explained by the GT. This type of non-verbal communication employs facial expressions and head movements to ensure that SwADHDs understand the GT's tasks and materials and understand the instructions given by the GT to SwADHDs (Dustin, 2015). The stern facial expressions shown by GT are made to give a warning, and smiling faces indicate that SwADHDs have: successfully followed instructions, can complete assignments, and understand the material. SwADHDs responses were also performed using facial expressions, smiling (if successful in completing the task, understanding the material), and a flat face when being reprimanded by GT. The type of non-verbal communication was a head movement by the GT ,nodding the head meaning "yes" and shaking the head meaning „no." The SwADHDs response also uses the same meaning as the GT's, namely nodding means „yes” and shaking the head means "no." This type of eye contact communication between the GT and SwADHDs aims to: reprimand, give advice and pay attention to SwADHD when studying. 
The SwADHD made eye contact when providing answers to the GT's questions. The touch communication was carried out by the GT when the SwADHDs followed advice so that they were motivated to learn.

The verbal and nonverbal communication between GTs and SwADHDs aims to invite SwADHDs to focus on doing tasks, starting with a call-using a hand wave- and then asking questions about the work done by SwADHDs. The SwADHDs response was made by eye contact and answering questions about assignments.

The type of communication in instructional activities, namely verbal communication between the GT and SwADHDs, aims to enable SwADHDs to: understand instructions and subject matter, pay attention and develop understanding, complete assignments, and understand social relationships with other friends in the class (Prevatt \& Levrini, 2015). This type of non-verbal communication between the GT and SwADHDs aims to make SwADHDs understand: the form of instruction, subject matter, and complete assignments (Iseman, 2012). Types of verbal and non-verbal communication between GTs and SwADHD encourage SwADHDs to understand instructions and work on assignments.

\section{Instructional Evaluation}

The instructional evaluation activities consist of three themes: verbal, non-verbal, and both verbal and non-verbal. The instructional communication between GT and SwADHDs occurs at the end of the instructional activity.

The types of verbal communication that occurred between GTs and SwADHDs consist of advice and reprimands. The purpose of the advice and reprimands given by GTs to SwADHDs is to ensure that SwADHDs carry out the instructions given by the GT. Verbally, the advice was given to SwADHDs to do the test honestly and not to cheat or ask other friends. The GT gave a warning when SwADHDs didn't do the test but annoyed their other friends. The response given by SwADHDs is usually done with non-verbal (body movements and eye contact) carried out the instructions repeated by the GT. For example:

GT: „SA, let's do your test, don't bother your friends."

SA: (stop annoying friends, and rework the test)

Non-verbal communication consists of emblems, facial expressions, head movements, eye contact, and touch. The purpose of the general type of non-verbal communication is that the GT ensures that all instructions given can be carried out by SwADHDs, and to provide advice. The communication through the emblem is carried out by the GT in the form of a wave of the hand when calling SwADHDs, going around to SwADHDs and being responded to by SwADHD by approaching the GT when called by the GT. Making facial expressions the GT signals to the SwADHDs using firm facial expressions when giving tests, giving warnings, and smiling facial expressions when the SwADHDs have finished working on the test. Meanwhile, the SwADHDs response was to give a smiling face when completing the test and a confused facial expression when they could not answer test questions. The GT's head movements consisted of nodding their head meaning "yes" and shaking their head as a sign of „no.” Responses provided by SwADHDs (NI and SA) were bowing their heads when reprimanded, shaking their heads when they said „no," and nodding their heads when they said „yes." The communication with eye contact that theGT made to SwADHDs occurred when the GT reprimanded, gave advice, gave test papers, and approached SwADHDs. SwADHDs gave the same responses to the GT. They made eye contact when invited to communicate with the GT. Touch is a type of non-verbal communication used when SwADHDs finished a test by inviting them to clap their hands together.

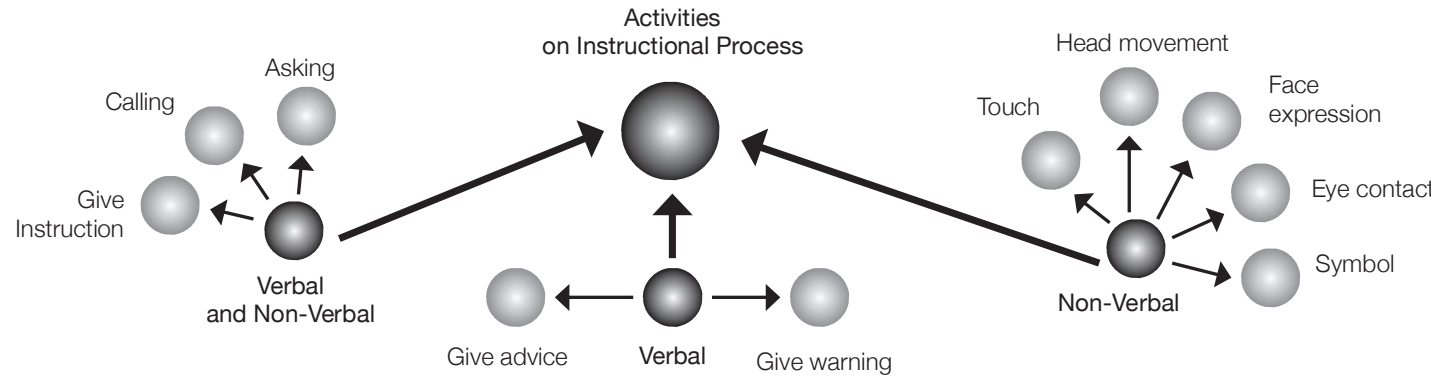

Figure 4.

Types of communication between SwADHD and DT in Instructional Evaluation Activities 
Types of verbal and non-verbal communication consist of calls, questions, and instructions. Verbal and non -verbal communication goals ensure that SwADHDs carry out instructions, understand test material, and provide reprimands. GT's type of call communication to SwADHDs includes verbal calls to SwADHDs to take test questions, collect test results, and reprimand SwADHDs. SwADHDs gave the next response by making eye contact with the teacher and carried out the GT's instructions. The type of questioning communication was carried out by the GT asking SwADHDs about the part of the test questions that SwADHDs did not understand. The GT also read out the test questions that SwADHDs did not understand verbally. SwADHD responded with eye contact and nodded his head as a sign of "yes" to the GT so they can read out questions that the GT does not understand. An example can be seen in the conversation with NI below:

\section{GT: "Is there any part that you do not understand in these questions? Do I need to read it out? \\ NI: (nods" agrees, and makes eye contact with GT)}

The type of instructional communication given by the GT to SwADHDs was instructing them to do the test, and if the SwADHDs did not understand, they could ask the teacher. The SwADHD responded by nodding their heads as a sign of „yes” or agreeing with the GT.

Types of verbal, non-verbal, and both verbal and nonverbal communication conducted between GTs and SwADHDs aim to ensure that SwADHDs carry out instructions and understand test questions.

\section{DISCUSSION}

The type of instructional communication between GTs and SwADHDs in an inclusive classroom is a form of interaction that aims to increase the student's knowledge and behavior. Furthermore, the ultimate goal of communication in instruction is to increase student success according to their respective needs and characteristics (Cornelius -White \& Harbaugh, 2010). The type of communication between teachers and students with special needs provides the possibility for educators (Andzik \& Cannella-Malone, 2019), in this case, GT, to strengthen the series of instructions given to SwADHDs. For example, verbal communication is one type of effective communication widely used by teachers in strengthening and clarifying instructions that students with special needs must carry out.
The instructional communication between GTs and SwADHDs in pre-instructional activities consists of verbal and non-verbal communication. The purpose of verbal communication carried out between GTs and SwADHDs is to provide enthusiasm, motivation, repeated instructions, and to improve socio-emotional relationships before learning begins. Encouraging and motivating $\mathrm{ADHD}$ students is one way to ensure they are more ready to start learning (Borkowska $\&$ Zawadz$\mathrm{ka}, 2008)$. GTs must provide direction and special treatment in positive sentences by providing a clear and concise picture so that SwADHDs understand what is being learned. Teachers can engage with ADHD students by singing, short and happy games, or guessing games, increasing student motivation and enthusiasm.

In addition to verbal communication, this type of non-verbal communication before learning aims to reinforce instructions, invite students to carry out the instructions given and to give praise to students ( $\mathrm{Du}-$ stin, 2015). In this case, the GT uses non-verbal communication types such as thumbs up and head nods to signal that SwADHDs have carried out the instructions well. Additionally, the use of thumbs and head nods as a form of praise to SwADHDs for carrying out the instructions well. Giving praise to ADHD students is one way to keep them focused and apply discipline regularly. On the other hand, shaking the head is a sign that the instructions have not been implemented properly. The use of verbal and non-verbal communication types in the pre-instructional stage is a type of communication between GT and SwAFHDs. Students are ready to engage in learning, have enthusiasm, motivation, focus, and sufficient attention to the subject matter being studied (Lestari, 2020). The emotional state of SwADHDs that have been well prepared will affect the social aspects of SwADHDs with other students.

In instructional activities, instructional communication between the GT and SwADHDs, whether it be, verbal, non-verbal or verbal and non-verbal has the same objectives. Verbal communication aims to remind SwADHDs to carry out tasks, ensuring that they understand and carry out instructions as directed by the GT (White, 2016). Another goal is to remind SwADHDs to focus on the material and tasks that are being carried out. ADHD students will be more easily distracted, so the GT needs to remind SwADHDS repeatedly to use verbal communication because it is more effective than non-verbal types of communication (Jacobs, 2016). In 
contrast to verbal communication, non-verbal communication is more emphasized as a symbol of reward giving, praise and affirmation of a condition, and agreement on an option (Lishman, 2009). The GT needs to affirm the conditions in learning activities so that SwADHDs understand the difference between what they can and cannot do. For example, shaking the head as a sign of "no,” on the other hand, "yes” as a sign of agreement, or of SwADHDs carrying out instructions correctly.

Similar to the type of non-verbal communication, verbal and nonverbal communication (combined) aims to ensure and provide affirmation in carrying out tasks and instructions correctly. All types of communication between GTs and SwADHDs in instructional activities describe the relationship between teachers and students. Instruction is of a higher quality; instructional targets can be achieved according to student needs. Additionally, it can improve students' socio-emotional state and prevent excessive behavior, especially in physical activity (walking in class, disturbing friends) (Schrodt, 2003). This type of communication in verbal evaluation activities aims to make SwADHDs: commit to doing tests/assignments given, provide affirmation to complete assignments, and provide warnings. The reminder is a communication tool that must be used by the GT so that SwADHD is focused and gives attention to the task or test that is being faced. This must be done repeatedly so that SwADHDs have a high level of commitment to solving it. Although it will be carried out continuously, verbal communication can be effective, especially in physical activities (Gorham, 1988; Rasmitadila et al., 2019), the more often the attention of SwADHDs is distracted, the role of the GT in reminding and reprimanding SwADHDs must be more frequent and it is to be done using positive statements and affirmative sentences. Short, simple, and easy to understand by SwADHDs.

Meanwhile, the non-verbal, verbal and non-verbal types of communication aim to ensure that SwADHDs have completed the assignment/test in the form of symbols -thumbs up \& head nod- which the GT did very clearly. Furthermore, it provides an understanding of what SwADHDs can or should not do. SwADHDs will find it easier to understand admonitions, warnings, and compliments in the form of stronger symbols. Like nodding your head as an agreement, and shaking your head as a sign of disagreement.

\section{CONCLUSION AND IMPLICATIONS}

Types of instructional communication between GTs and SwADHD that occur during the pre-instructional, instructional process, and instructional evaluation use verbal, non-verbal, and verbal and non-verbal communication types (combined). The instructional communication improves the positive socio-emotional relationship between GTs and SwADHDs and also between SwADHDs and general students. Additionally, it can reduce the negative behavior that SwADHDs often display in the classroom and improve instructional quality, SwADHDs can achieve quality education goals according to their characteristics and needs.

The type of communication between GTs and SwADHDs has a large impact on teachers in making individual learning programs that are more fit for purpose in the handling of SwADHDs both academically and non-academically. For this reason, it will be more effective and targeted if a special unit is formed in schools to provide services, especially in making learning programs that focus more on improving behavior so that it can have a positive impact on the future of SwADHDs.

\section{ACKNOWLEDGEMENT}

None.

DISCLOSURE STATEMENT

No potential conflict of interest was reported by the authors.

\section{FUNDING}

None.

\section{REFERENCES}

Andzik, N. R., \& Cannella-Malone, H. I. (2019). Practitioner Implementation of Communication Intervention With Students With Complex Communication Needs. American Journal on Intellectual and Developmental Disabilities, 124(5), 395-410. https://doi.org/10.1352/1944-7558-124.5.395

Barkley, R. A., \& Poillion, M. J. (1994). Attention deficit hyperactivity disorder: A handbook for diagnosis and treatment. Behavioral Disorders, 19(2), 150-152.

Borkowska, A., \& Zawadzka, E. (2008). Verbal working memory in ADHD children. Psychology of Language and Communication, 12(1). https://doi.org/10.2478/v10057-008-0004-z 
Boyce, S. (2017). The Causes of Non-Verbal Communication Problems. In S. Boyce, Not Just Talking (1st ed., pp. 37-46). Routledge. https://doi.org/10.4324/9781315169255-3

Clarke, V., Braun, V., \& Hayfield, N. (2015). Thematic analysis. Qualitative Psychology: A Practical Guide to Research Methods, $222-248$.

Cornelius-White, J., \& Harbaugh, A. (2010). Learner-Centered Instruction: Building Relationships for Student Success. SAGE Publications, Inc. https://doi.org/10.4135/9781483349183

Dasrial, A., Sarmiati, S., Afrizal, A., \& Zainal, Z. (2020). Construction of a Symbolic Meaning of Greetings Kissing the Palm and Back of the Teacher's Hand by the Santri Ponpes Nurul Yaqin. AL MUNIR: Jurnal Komunikasi Dan Penyiaran Islam, 1-17.

Dustin, Y. (2015). Non-verbal immediacys role in student learning. Journal of Media and Communication Studies, 7(1), 1-7. https://doi.org/10.5897/JJMCS2014.0416

Farida, N., \& Friani, D. A. (2018). Analysis of the Benefits of Peer Interaction on Early Childhood Social Behavior in Ra Muslimat Nu 007 Gandu 1 Mlarak, Ponorogo Regency, East Java Province.1, 86-91.

Fuentes, S. Q., Crawford, L., \& Huscroft-D’Angelo, J. (2017). Reasoning for all: An instructional model. Australian Primary Mathematics Classroom, 22(3), 20-25.

Gorham, J. (1988). The relationship between verbal teacher immediacy behaviors and student learning. Communication Education, 37(1), 40-53. https://doi.org/10.1080/03634528809378702

Hamilton, N. J., \& Astramovich, R. L. (2016). Teaching strategies for students with ADHD: Findings from the field. Education, 136(4), 451-460.

Humairah, S. (2017). Teacher Interpersonal Communication to Students Attention Deficit Hyperactivity Disorder (ADHD) at the Special School for Independent Children in Serang City.

Iseman, J. S. (Ed.). (2012). School Success and Cognitive Instruction for Students with ADHD. The ADHD Report, 20(1), 1-6. https://doi.org/10.1521/adhd.2012.20.1.1

Jacobs, G. (2016). 26. Verbal communication quality in institutional contexts. In A. Rocci \& L. de Saussure (Eds.), Verbal Communication. De Gruyter. https://doi.org/10.1515/9783110255478-027

Kennedy, C. H. (2005). Single-case designs for educational research. Prentice Hall.

Laasonen, M., Väre, J., Oksanen-Hennah, H., Leppämäki, S., Tani, P., Harno, H., Hokkanen, L., Pothos, E., \& Cleeremans, A. (2014). Project DyAdd: Implicit learning in adult dyslexia and ADHD. Annals of Dyslexia, 64(1), 1-33.

Lestari, V. L. (2020). The Role of Parental Attention and Learning Motivation in Increasing Students' English Learning Achievement. Seltics, 3(1), 12-21. https://doi.org/10.46918/seltics.v3i1.540

Lishman, J. (2009). Types of communication: Symbolic, non-verbal and verbal. In J. Lishman, Communication in Social Work (pp. 25-53). Macmillan Education UK. https://doi.org/10.1007/978-1-137-11803-5_3

Liu, L. (2011). An international graduate student's ESL learning experience beyond the classroom. TESL Canada Journal, 77-92.

Moeller, J. D., Dattilo, J., \& Rusch, F. (2015). Applying quality indicators to single-case research designs used in special education: A systematic review. Psychology in the Schools, 52(2), 139-153.

Óskarsdóttir, E., Donnelly, V., Turner-Cmuchal, M., \& Florian, L. (2020). Inclusive school leaders-their role in raising the achievement of all learners. Journal of Educational Administration.

Patton, M. Q. (2014). What brain sciences reveal about integrating theory and practice. American Journal of Evaluation, 35(2), $237-244$.

Prevatt, F., \& Levrini, A. (2015). Case study: ADHD coaching with a college student with executive functioning deficits. In F. Prevatt \& A. Levrini, ADHD coaching: A guide for mental health professionals. (pp. 171-188). American Psychological Association. https://doi.org/10.1037/14671-011

Rasmitadila, R., Samsudin, A., \& Prasetyo, T. (2019). Teacher-Students' Instructional Interactions Analysis (TSIIA): A Case Study in Inclusive English Classrooms in Indonesia. The International Journal of Interdisciplinary Educational Studies, 14(1), 1-22. https://doi.org/10.18848/2327-011X/CGP/v14i01/1-22

Reebye, P. (2008). Attention-Deficit Hyperactivity Disorder: A Handbook For Diagnosis And Treatment. Journal of the Canadian Academy of Child and Adolescent Psychiatry, 17(1), 31.

Rief, S. F. (2012). How to reach and teach children with ADD/ADHD: Practical techniques, strategies, and interventions (Vol. 3). John Wiley \& Sons.

Rodríguez, C., Areces, D., García, T., Cueli, M., Loew, S. J., \& González-Castro, P. (2015). ADHD and Writing Learning Disabilities: Overlapping Disorders and Educational Implications. Insights into Learning Disabilities, 12(2), 121-146.

Rosita, T., Rakhmat, C., \& Soendari, T. (2020). Role of Parent Interaction On The Social Skills Of Primary School Students Having ADHD Obstacles. COLLASE (Creative of Learning Students Elementary Education), 3(3), 82-90.

Ross, P., \& Randolph, J. (2016). Differences between students with and without ADHD on task vigilance under conditions of distraction. Journal of Educational Research and Practice, 4(1), 1-10.

Russell, A. E., Moore, D. A., \& Ford, T. (2016). Educational practitioners' beliefs and conceptualisation about the cause of ADHD: A qualitative study. Emotional and Behavioural Difficulties, 21(1), 101-118.

Saussure, L. de, \& Rocci, A. (2016). 1. Verbal communication. An introduction. In A. Rocci \& L. de Saussure (Eds.), Verbal Communication De Gruyter. https://doi.org/10.1515/9783110255478-002

Schrodt, P. (2003). Student perceptions of instructor verbal aggressiveness: The influence of student verbal aggressiveness and self-esteem. Communication Research Reports, 20(3), 240-250. https://doi.org/10.1080/08824090309388822

Shillingford-Butler, M. A., \& Theodore, L. (2012). Students diagnosed with attention deficit hyperactivity disorder: Collaborative strategies for school counselors. Professional School Counseling, 16(2_supply), 2156759X12016002S05.

Sjöberg, M. N., \& Dahlbeck, J. (2018). The inadequacy of ADHD: a philosophical contribution. Emotional and Behavioural Difficulties, 23(1), 97-108.

Tannock, R. (2018). ADHD and communication disorders (Vol. 1). Oxford University Press. https://doi.org/10.1093/med/9780198739258.003.0028

Treharne, G. J., \& Riggs, D. W. (2015). Ensuring Quality in Qualitative Research. In P. Rohleder \& A. C. Lyons (Eds.), Qualitative Research in Clinical and Health Psychology (pp. 57-73). Macmillan Education UK. https://doi.org/10.1007/978-1-137-29105-9_5

Tuckman, B. W., \& Harper, B. E. (2012). Conducting educational research. Rowman \& Littlefield Publishers.

Wei, X., Yu, J. W., \& Shaver, D. (2014). Longitudinal effects of ADHD in children with learning disabilities or emotional disturbances. Exceptional Children, 80(2), 205-219.

White, P. R. R. (2016). 5. Evaluative contents in verbal communication. In A. Rocci \& L. de Saussure (Eds.), Verbal Communication De Gruyter. https://doi.org/10.1515/9783110255478-006 